\title{
JUAN CAMPESINO
}

Centro Nacional de Investigación Teatral Rodolfo Usigli (INBAL)

jcretes@yahoo.com.mx

\section{Semiótica de La NANOTEATRALIDAD Semiotics of nano-theatrality}

El presente artículo se ocupa del módulo semiótico de la teatralidad, misma que reduce a su mínima expresión con el objeto de que se comprenda que lo teatral se vierte sobre el signo lingüístico irónico. Éste último se comprende, en suma, como reducción semiótica de aquel, cuyos componentes se vuelcan sobre las funciones lingüísticas de combinación y selección, que deriva en una clase de lenguaje que articula negativamente una semiótica connotativa en su expresión y una metasemiótica no científica en su contenido.

PALABRAS CLAVE: Teatralidad, ironía, figuración, mención ecoica, diacrítica, parodia, sátira.

This paper looks upon the semiotic module of theatrality, which it reduces to its minimal expression in order to explain that the theatrical turns over the ironical linguistic sign. It comprehends this, ultimately, as the semiotic reduction of that, of which components turn over combinative and selective linguistic functions deriving in a type of language that negatively articulates a connotative semiotic in its expression and a non-scientific metasemiotic in its content.

KEYWORDS: Theatrality, irony, figuration, echoic mention, diacritics, parody, satire.

\section{Preliminares}

Cuando se habla llanamente de una semiótica del teatro o de una semiótica teatral (v. gr., De Toro, y Fischer-Lichte), tiende a caerse en el supuesto de que el teatro constituye un sistema de signos autónomo apto en todo para sustituir al sistema de la lengua. El sentido más tradicional de la palabra semiótica (ver Martinet: 110) comprende este factor sustitutivo del objeto de estudio, en el que, en cualquier caso, 
se debe identificar la dualidad significante/significado y, en especial, la clase de convención que los une. En tanto que disciplina académica, la semiótica se programó como la ciencia que estudia todos aquellos sistemas de comunicación susceptibles, por su carácter convencional y su constitución biplana, de sustituir de modo integral al sistema de la lengua (ver Eco: 63-66), para cuyo estudio ya se contaba con el término lingüistica. Cierto, hoy día la semiótica ha llegado a considerar la lingüística como una más de sus ramas de estudio, donde el sistema de la lengua ocupa una posición jerárquica análoga a la del sistema de la moda, por ejemplo (ver Barthes). No me sorprende, dada la diferencia de amplitud semántica entre ambos vocablos, y tampoco me opongo, pues en nada atenta contra el criterio de la sustitución; ha vindicado, si acaso, el paralelismo jerárquico de unos sistemas y otros, así el de la escritura, de siempre considerado un sucedáneo imperfecto de la lengua hablada (ver Fedro: 274d-275b; Derrida: 93-260; Wolf: 90-100). En este sentido, toda semiótica teatral habría de vérselas con una teatralidad dividida en dos planos y en la que ninguno de los dos planos es estrictamente lingüístico, lo que no ocurre por la sencilla razón de que toda representación teatral se lleva a efecto en una lengua específica. Para hablar, en suma, de una semiótica teatral habría que desechar la lengua y encontrar una acción pura compuesta de un significante y un significado convencionales pero no lingüísticos, empresa que, tratándose de un género de representación en el que la palabra es acción, resulta a todas luces vana, cuando no imposible.

Más plausible me parece, por ello, hablar de un módulo semiótico de la teatralidad, si bien en un sentido restringido atinente a la clase de figuración que se pone en juego. Quiero decir que, en términos semióticos, la teatralidad corresponde a una clase particular de signos lingüísticos y que dicha clase se circunscribe a un registro figurado de la significación. ${ }^{1}$ Se trata - lo han sabido autores tan disímbolos y de estaturas tan variadas como Soren Kierkegaard, Connop Thirlwall, Garnett

${ }^{1}$ En otro sitio (ver referencia) me ocupo de distinguir el lenguaje de uso, o sentido literal, de los diversos grados posibles de figuración lingüística, y digo "lingüística" en el entendido de que, en el seno del lenguaje, toda figuración depende específicamente de cierto empleo, anómalo, si se quiere, de los principios más elementales de la lengua en tanto que sistema. Me refiero, desde luego, a los principios de selección y de combi- 
Sedgewik y Marlena Creseure- de la figuración irónica o, dicho llanamente, de la ironía. Aspiro a resultar, empero, innovador ahí donde, para reducir la teatralidad a la semiosis irónica, lo teatral a la ironía, me comprometo a ampliar también la semiosis irónica al tamaño de la teatralidad. De otro modo: explicaré la ironía como una semiosis, es decir, como una convención lingüística correlativa a un significante y un significado y, de manera paralela, demostraré que dicha convención no es otra cosa que lo teatral en tanto que horizonte semiótico. Emplearé para ello un enunciado que, reduciéndola a su mínima expresión, evidencia que, antes que de habla, la ironía constituye un hecho de lengua, una función del texto antes que del contexto, una función que concentra lo teatral (lo escénico, lo dramático, lo cómico, lo trágico) en una unidad semiótica susceptible, por ende, de definirse y explicarse de manera integral sin abandonar los linderos del significante y el significado. Con este objeto, y echando mano de algunas nociones básicas de la lingüística formalista, caracterizaré en lo esencial los cuatro aspectos sígnicos de la ironía: (1) el bivocal, que corresponde a su carácter de cita internamente contrastada, en particular de mención ecoica; (2) el dialógico, en atención a su función diacrítica; (3) el retórico, donde opera como imitación estilizada, como parodia, y (4) el tópico, donde se materializa como crítica velada, como sátira.

Saussure (127-30) define el signo lingüístico como una entidad formal en la que coactúan una imagen acústica y una imagen conceptual. Es formal desde que el análisis empírico de los incontables materiales con que pueden configurarse ambos planos resulta insuficiente para hablar de un sistema de los sonidos y las grafías o de un sistema de las percepciones y los pensamientos, lo que desde luego no ocurre en el caso de los fonemas o de los pronombres. Saussure se propone acceder a la forma común que habría de entrelazar materiales tan dispares como son los sonidos y los conceptos y que, para él, debiera constituir el sistema de la lengua. A Hjelmslev le bastará, por su parte, profundizar en el análisis para darse cuenta de que no se pueden explicar los aspectos sonoro y conceptual de la lengua a partir de una forma única. Donde el suizo

nación o, de otro modo, a los ejes paradigmático y sintagmático que articulan el sistema de la lengua con los procesos del habla. 
veía una sola forma para dos sustancias distintas, Hjelmslev encontró dos formas, correspondientes a las dos sustancias, y las llamó forma de la expresión y forma del contenido. No habiendo, empero, otros medios factibles para acceder a dichas formas que los sonidos y los conceptos, la glosemática se vio en la necesidad de contemplar en el análisis las sustancias de ambos planos y, para ello, las despojó de toda realidad material y las integró como variables, como constituyentes del proceso mediante el que se actualiza el sistema. ${ }^{2}$ Resulta imposible, en efecto, hablar sistemáticamente de la sustancia si no es en términos formales (ver Hjelmslev 1972: 65), de modo que a los dos niveles, formal y sustancial, identificados tradicionalmente, el danés añadió un tercero, el de la materia, con el objeto de reducir la sustancia a sus rasgos formales y la forma a un conjunto de interrelaciones entre unidades (ver Ducrot y Todorov: 37$){ }^{3}$

${ }^{2}$ Bien dice Eugenio Coseriu (184-86) que el término sustancia lo emplea Hjelmslev en dos sentidos distintos, sea que se refiera al material acústico o conceptual amorfo e incognoscible del que se compone el habla o bien a la variabilidad de una manifestación lingüística.

${ }^{3}$ El principio estructural de Hjelmslev se atiene a la distinción entre el sistema de la lengua y los procesos que se derivan de él. Opina este autor que el proceso corresponde a la realización de la forma, a la determinación del sistema lingüístico, entendido como abstracción de la materia con que se compone la lengua, y que juntos cumplen una función sígnica. Según esta perspectiva, el proceso dependería de la existencia del sistema, y no viceversa: "Es inimaginable un proceso [...] sin un sistema existente tras él. En cambio, no es inimaginable un sistema sin un proceso; la existencia de un sistema no presupone la existencia de un proceso. El sistema no adquiere existencia en virtud del hallazgo de un proceso" (1974: 62). En cualquier caso, la forma determina la sustancia y se proyecta sobre ella "de igual modo que una red abierta proyecta su sombra sobre una superficie sin dividir" (85). La distinción, que el danés explica en los términos de lengua y texto, se verifica así en el plano de la expresión como en el del contenido, cada uno de los cuales observa un aspecto formal, o sistémico, y un aspecto sustancial presente en el proceso. Del todo inútil resulta, a propósito, tratar de establecer un sistema de los materiales con que se puede pintar un retrato, un inventario ordenado de todas las tierras, pigmentos, bases, instrumentos y superficies empleados en la composición de retratos; tampoco las personas reales que aparecen o pueden aparecer retratadas son susceptibles de ordenarse en clases y categorías. En cambio, un análisis cenemático de los retratos se ocupará de la cromática y la plástica, de los colores empleados y, en particular, de las interrelaciones mediante las que dichos colores adquieren la forma de un retrato, mientras que su descomposición pleremática atenderá a los mecanismos que hacen de un conjunto de volúmenes la representación de un personaje de cierto género, edad y condición. 


\section{El signo irónico}

Es en consideración de lo anterior que, al igual que toda figuración, la ironía se presta para ser explicada como una unidad lingüística que opera de un modo específico. He escogido para ello un ejemplo que, eludiendo el imperativo de contradicción contextual que empaña la comprensión del fenómeno desde tiempos de Quintiliano, resulta particularmente esclarecedor. En el cuento "El perseguidor" (1959), de Julio Cortázar, el protagonista Johnny Carter, al recibir la visita de su amigo el escritor, exclama: "El compañero Bruno es fiel como el mal aliento", una comparación cuyo matiz irónico dista mucho de suponer una contradicción o bien de precisar de un contexto para darse a entender, pues, en dado caso, la ironía es inmanente a la frase. ${ }^{4}$ Lejos del antagonismo o la antífrasis, aquí la fidelidad y el mal aliento aparecen unidos por otra clase de nexo y separados por otro tipo de controversia.

De entrada, para alguien que sepa español, la cadena significante [fiel como el mal aliento] difícilmente opondrá resistencia a la hora de reducir el repertorio e identificar el código. El escollo se presenta, no obstante, en el ingreso al contenido, pues cierta cualidad de la expresión sugiere que, pese a estar unidos por un nexo de identidad, entre el

4 Para Hjelmslev, el fonema de la escuela de Praga resulta inadecuado por incorporar únicamente el aspecto fónico de las manifestaciones lingüísticas en detrimento de todos los demás (gráfico, táctil, gestual...), de ahí que prefiera llamar cenemas a estas figuras constituyentes de la expresión, que a su vez opone a los prosodemas, o exponentes mínimos del plano cenemático. Se referirá, asimismo, a los constituyentes mínimos del contenido como pleremas (semas, para otras escuelas) y a sus respectivos exponentes como morfemas. El cenema pertenece al repertorio convencional de la expresión; es intralingüísico (cfr. Hjelmslev 1987: 219). Tiene su contraparte material en el prosodema: unidad física de sonido compuesta de acento y modulación (267) y distribuida en tono, intensidad, timbre y duración (ver Collado: 197). Por su parte, el plerema corresponde a las nociones tradicionales de lexema y derivativo, ligadas a la sustancia conceptual, mientras que el morfema posee un significado eminentemente gramatical (para una exposición clara y concisa de la terminología glosemática, ver Alarcos Llorach: 17-47). En lo personal, prefiero la denominación morfema para agrupar tanto lexemas y derivativos como los llamados gramemas, reservándome el término plerema para las unidades resultantes de la suma de los significados léxico, gramatical y conceptual. De manera paralela, emplearé el término constituyente para referirme a las unidades sustanciales de cada plano: prosodemas y pleremas, y exponente para hablar de las unidades formales: cenemas y morfemas. 
prosodema fiel y el prosodema mal aliento se erige una pared, cualidad en estrecha relación con la escasez de probabilidades de que ambas palabras aparezcan combinadas en el discurso. ${ }^{5} \mathrm{~A}$ la luz de esta sugerencia, susceptible de manifestarse, dado el caso, mediante una gran variedad de indicadores (cfr. Muecke 1978), los prosodemas chocan entre sí, resultando mutuamente inadecuados desde que no forman parte de un mismo género discursivo sino que, a través de ellos, se expresan dos discursos, dos voces distintas en todo equivalentes, teatralmente hablando, a las voces del actor y del personaje. El lector comprende de inmediato que una de estas voces se ha tomado prestada de un repertorio ajeno al ámbito estilístico de la otra y que, más que la voz de esta habla ajena, lo que escucha es su eco, una réplica que resuena con algún grado de distorsión o, de otro modo, una mención ecoica (cfr. Sperber y Wilson 1978: 1981). ${ }^{6}$ Se trata de una clase de bivocalidad que desequilibra la forma y autoriza al lector a desconfiar de ella, a hacerla resonar con un nuevo temple y, con miras a recuperar la naturalidad, a elevarla a una potencia fraccionaria. ${ }^{7}$ ¿Cómo lo hace? Relativizando uno de los extremos de la oposición, entrecomillándolo, donde las comillas actúan

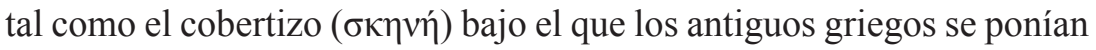
en escena.

A continuación, el lector se pregunta por la función que atañe a una forma significante internamente contrastada o, en términos bajtinianos, internamente dialógica, y entonces regresa sobre sus pasos para revisar

5 El hecho de que, aunque bajas, haya probabilidades de que los dos términos aparezcan en un mismo contexto lingüístico determina la pertinencia de la expresión en el marco del sistema. La coexistencia de las formas es, no cabe duda, anómala, pero no imposible pues, si escasa, la probabilidad aún autoriza su mutua correlación, por eso dice John Lyons que "la importancia de un determinado contraste está relacionada con su frecuencia de aparición" (84). Con todo, su coexistencia en el sintagma atenta contra las máximas de modo que, según Grice, regulan el uso del lenguaje en la conversación y que, entre otros, incluyen el compromiso de evitar la ambigüedad, como la que sin duda resulta de comparar la fidelidad con el mal aliento.

${ }^{6}$ Para una tipología de las menciones, ver Berrendonner: 163-79.

7 También el principio de alteración del equilibrio que, extrapolándolo de la física relativista, Eugenio Barba sitúa como eje rector de su antropología teatral, comprende un movimiento de ruptura y, simultáneamente, un impulso de reconstrucción, toda vez que se "renuncia a un balance cotidiano en favor de un equilibrio precario o extracotidiano" (Barba y Savarese: 32. Mía la traducción). 
los constituyentes de la expresión, ya que dos voces en una cadena significante pueden hablar juntas o bien hablar la una con la otra (ver Bubnova: 110-12). Dos voces pueden defender la misma causa, el conectivo como así lo indica, pero también pueden desacordar para entablar entre ellas una polémica oculta. El contraste interno de la forma señala que, antes que juntas, las voces fiel y mal aliento se encuentran frente a frente, intercambiando sus criterios divergentes o, en suma, criticándose mutuamente. Para que ello ocurra, asegura Pere Ballart (313-16), ambos términos deben coincidir en un campo de observación, deben pertenecer, como las dos premisas de un silogismo, a un mismo orden sintáctico o, en palabras de Lyons, ser parcialmente equivalentes, lo que se observa en que ambos poseen un sentido nominal. ${ }^{8}$ De este modo, ahí donde el proceso de denotación supone una relación sintagmática de la cadena significante con un contenido situado en el exterior, en este caso se trata de una oposición que, mediante un contraste entre sus partes, divide la cadena al interior, haciendo de ella, literalmente, un escenario en el que — parafraseo a Nietzsche (2000: 86) — la palabra se ve transformada a sí misma delante de sí, y actúa como si realmente hubiese penetrado en otra palabra, en otro cuerpo y otro carácter. Amparado en el sentido más elemental del término, llamo diacrítica a este drama de la palabra, a este acontecimiento que - y ahora es Hegel (141) a quien cito- "no parece nacer de las circunstancias exteriores, sino de la voluntad interior" de la expresión. ${ }^{9}$

8 "Dos unidades — dice el británico - no pueden guardar contraste a menos que sean parcialmente equivalentes en distribución (a las unidades en distribución complementaria no incumbe el problema del contraste)" (73). Son distribucionalmente equivalentes dos unidades que aparecen en la misma clase de contextos, mientras que las unidades que no tienen contextos en común poseen una distribución complementaria. Entre estos dos polos, el autor distingue dos tipos de equivalencia parcial: cuando una de las unidades acompaña siempre a la otra, pero no viceversa, y por ende su distribución está incluida en la de ésta, y cuando hay algunos contextos en que la unidades aparecen juntas pero ninguna de las dos aparece siempre junto a la otra (71). Es esta última clase de distribución, parcialmente superpuesta, la que se observa en la expresión que nos ocupa.

${ }^{9}$ Por su parte, Emil Staiger coincide con Hegel a propósito de lo dramático, estilo que, en oposición al lírico y al épico, resulta para el suizo de una tensión que se manifiesta "en virtud de la interdependencia de las partes" (170). 
Por lo que hace al plano del contenido, una vez comprendido que el mal aliento no es fiel, el lector supone que el exponente fiel como el mal aliento se refiere a una sustancia a la que corresponden otras formas de contenido, tales como pertinaz como el mal aliento o indeseablemente fiel. Al recaer en él, el eco restringe la forma de significar del morfema fiel, socavando los rasgos semánticos, moralmente positivos, que se refieren a la virtud y enfatizando los rasgos conductuales que atañen a la persistencia. Asimismo, al subrayar el rasgo moral de la inconveniencia y soslayar el aspecto físiopatológico relativo a su etiología, las comillas conducen a una reducción del morfema mal aliento. ${ }^{10}$ Este filtrado, insisto, depende directamente de las posibilidades combinatorias de los morfemas, de ahí que difícilmente hayan de leerse los pleremas [devoto como el mal aliento] o [fiel como la indigestión]. En el caso dado, ambas partes de la cadena se formalizan como mención, si bien, dada la función negativa de la figuración irónica, el eco recae solamente en una de ellas, que en consecuencia adopta los rasgos negativos de la otra. Mediante su atribución a un habla ajena, el morfema fiel se convierte en una réplica distorsionada de la forma que le sirve de máscara, cuya sustancia incluye necesariamente todos sus rasgos o, cuando menos, los principales, entre los que se cuentan la virtud y la devoción. La forma original designa un constituyente específico, estandarizado, que bien puede referirse a un marido que no engaña a su esposa o a un parroquiano de firmes creencias, mientras que la réplica, relacionada con el mal aliento, probablemente posee un significado distinto, más acorde con el de los constituyentes [obstinado] o [pertinaz]. Se trata de una forma semejante al original que, mediante el contraste, se asocia con un material semántico distinto o, dicho llanamente, que significa otra cosa. Sobre esta base se comprenderá que, en lo tocante a la forma del contenido, la ironía se expone como parodia; es decir, como refuncionamiento cómico de un dispositivo mecanizado (cfr. Tinianov; Rose: 119), donde la mecanización se halla en el dispositivo fiel, y el refuncionamiento, en la comicidad que adquiere tras pasar por el filtro del binomio mal aliento.

10 Según se sigue, los criterios relacionales de la ironía, que aquí orbitan entre lo moral, lo conductual y lo fisiológico, caben en cualesquiera ámbitos conceptuales que se presten a valoraciones diversas. 
El desequilibrio debido a la disparidad interna de la expresión ocasiona que, en lugar de contrastarse con otros exponentes hasta distinguirse con claridad, la forma del contenido busque un exponente distinto del que pueda tomar prestada una sustancia más apta para establecer, sin traspasar los límites del sistema, una relación sintáctica, un sentido, pues. Para acceder al significado, el lector debe relacionar la forma replicada fiel con otra más pertinente para calificar al mal aliento, misma que probablemente será del tipo de obstinado o pertinaz. Se percata de la anomalía porque lo que parece un elogio, la forma fiel, es de inmediato sojuzgado por la forma mal aliento, cuya sustancia se compone eminentemente de rasgos negativos, algunos de ellos opuestos, inclusive, a los de aquella, pero también percibe que la inadecuación no es radical, que los constituyentes semánticos [fiel] y [mal aliento] comparten un rasgo específico: la persistencia. Ocurre lo siguiente: la sustancia del exponente fiel no sólo se reduce a la persistencia, término medio de su vínculo con el constituyente [mal aliento], sino que adquiere rasgos de éste, como lo indeseable y lo inconveniente, y se desplaza gradualmente hacia la sustancia de una forma como chocante o desagradable, si bien, sujeta a sus propios rasgos sustanciales, probablemente no llegue a tal extremo y se estabilice en un material semántico más acorde con el de los las formas pertinaz u obstinado. Así, mediante el contraste de su semejanza, el constituyente [mal aliento] afecta críticamente al exponente fiel hasta convertirlo en una réplica de sí mismo, cuya sustancia es más bien [pertinaz]. El lector lee, en suma, el morfema fiel como el mal aliento y, en aras de demarcar la sustancia y restaurar la naturalidad, lo relaciona de inmediato con un plerema cercano a [pertinaz como el mal aliento], para luego comprender que a esa sustancia unitaria corresponden dos exponentes distintos: pertinaz como el mal aliento y fiel como el mal aliento, con la salvedad de que, tras la máscara de esta segunda forma, a la vez simulación y disimulación, se oculta una crítica si no tan agresiva como la de la primera, sí más certera. En virtud de este movimiento final, la fidelidad de Bruno es cuestionada, convertida secretamente en obstinación, en terquedad, quizá en algo peor. No a otra cosa se refiere, creo, la palabra sátira, como aquella de que, desde el inicio del drama, se hace objeto la honorabilidad de Edipo, noble como el incesto y el parricidio (nótese el paralelismo de mi ocurrencia con 
la frase que ahora nos ocupa), y que no consiste sino en una reducción semiótica de la tragedia en cuestión.

En términos generales, la ironía pone en escena una forma expresiva semejante a otras, en este caso la del elogio fiel como un buen marido, pero que contiene en su interior un grado de contraste, un drama del que el lector se percata de inmediato y que lo conmina a oponer dos constituyentes expresivos semejantes, a juzgar por el nexo que los une. ${ }^{11}$ Este conflicto deriva en una contaminación de la forma de contenido, convertida ya en una réplica paródica cuya comicidad apunta a un constituyente semántico distinto $\mathrm{y}$, en consecuencia, a otro objeto del mundo, a un objeto que, no obstante, se burla soterradamente mediante un rodeo satírico (cfr. Worcester: 29-30, 77; Frye: 223 ss.; Pérez Lasheras: 79, 81) hasta poner ante los ojos del lector la tragedia que, lingüísticamente hablando, resume el hecho de que para una misma sustancia de contenido existan cuando menos dos formas distintas. ${ }^{12}$

${ }^{11}$ Llamo semejanza a la relación que media entre las unidades de un sintagma, en correspondencia con la variabilidad que Hjelmslev (cfr. 1974: 90-108) atribuye al proceso respecto del sistema y, en oposición, entiendo la invariabilidad de las unidades del sistema como una cualidad de distinción entre los miembros de un paradigma.

${ }^{12} \mathrm{Y}$ aquí me refiero a lo trágico y a lo cómico en sus sentidos más primordiales. Entiendo, a propósito, la comedia como lo hace Ana Rosa Domenella, es decir, como la "voluntad de hacer reír [que] comprende el conjunto de técnicas empleadas con dicho fin en diversos lenguajes" (85), y concuerdo con Henri Bergson (78-82) en que dichas técnicas bien pueden reducirse a tres procedimientos elementales; éstos son: la repetición, la inversión y la interferencia de las series, mismos que, según lo expuesto, se identifican con facilidad en el accionar de la parodia. Por cuanto a la tragedia, me remito tanto a la concepción de Aristóteles, quien la define como una sucesión de acontecimientos que transita del error (hamartia) a la obstinación (hybris), de ahí al reconocimiento (anagnórisis) y al cambio de fortuna (peripecia) que conduce a la desgracia (catástrofe), para ocasionar finalmente una liberación expiatoria del espectador (catarsis); todos ellos, atributos de la sátira que, para su desgracia, descubre que el lenguaje no cuenta con una forma única para cada sustancia, que tiende al error, pues, pero que asimismo se libera de toda culpa al no inclinarse definitivamente por ninguna de las formas. En este sentido cabe también traer a colación los postulados de Hegel (176-77), para quien la tragedia surge de un conflicto de intereses cada uno de los cuales enarbola su propio derecho en detrimento de su contraparte, lo que a la luz de lo social conduce inevitablemente al choque de ambas fuerzas que, por oposición al ideal de armonía, caen consecuentemente en culpa. Coincido, en cualquier caso, con Northrop Frye (224) cuando concibe la sátira en tanto que residuo no heroico de la tragedia. 
Por su parte, la reconstrucción de un sentido denotado inicia con la demarcación formal de una cadena significante, que así comienza por distinguirse de otras mediante una reducción que transita del repertorio ilimitado del lenguaje a los catálogos finitos de la lengua, del nivel fonético al fonológico, y acto seguido le atribuye una función acorde con su apariencia, de manera que la expresión se convierte en una forma de contenido que, por contraste con otras formas del repertorio morfológico, se proyecta sobre una sustancia semántica unitaria. En un movimiento de vaivén, el sentido denotado transita primero hacia afuera, de la sustancia a la forma, del material fónico a su contorno, y luego hacia adentro, de la forma a la sustancia, del término al concepto; semejante simetría allana, claro, las correspondencias formales entre dos materiales diversos. ${ }^{13}$ A cambio, la semiosis irónica opera desde el momento en que lo que aparece como una cadena en realidad da cuenta de una dualidad contrapuesta. La dualidad interna se convierte en un paradigma con el que tiene que lidiar la sustancia expresiva, un paradigma que, oponiendo las variables del proceso, se funda en la semejanza más que en la distinción. No se trata ya del contraste de una unidad con otras probables, sino del contraste interno entre dos partes de la cadena que, como resultado, se contaminan la una a la otra. A su vez, esta crisis, instaurada como forma del contenido, en lugar de distinguirse por contraste de otras formas léxico-gramaticales, se asocia con un constituyente semántico distinto que opera ya en el terreno de lo formal, interferencia que se completa cuando la sustancia lógico-semántica se sitúa en el punto de encuentro de dos exponentes morfémicos distintos. En suma, el sentido irónico viaja de una forma de expresión que, al proyectarse sobre la sustancia expresiva, se vuelve dual hacia adentro, a una sustancia semántica que, oscurecida por la forma de contenido, se biparte hacia afuera.

Lo que distingue a la ironía de otros signos es la naturaleza de la articulación entre sus cuatro niveles semióticos, que en su caso comprende un procedimiento dialéctico/dialógico motivado por la crisis tanto ex-

${ }^{13}$ A causa de esta correspondencia se dice que los planos de la expresión y del contenido de un signo denotativo son isomorfos; es decir que "contraen relaciones de solidaridad y complementaridad o, de otra manera, que son interdependientes: a una forma de la expresión corresponde una forma de contenido y sólo una" (Pascual Buxó: 29). 
presiva como semántica de la forma y la sustancia, una operación que, tras cristalizar en una síntesis, se disemina en una réplica (así llamamos, en el teatro, a los parlamentos opuestos), ya que el resultado obtenido no alcanza a hacerse presente, permaneciendo, como hace, en la sombra. Se trata de una diacrítica y no de una antífrasis desde que el lance integra una sumatoria, representada en la cita por el conectivo como; más que restar cifras positivas, la ironía suma, a una cifra positiva, una cifra negativa, un valor no natural cuyo producto deriva en un número imaginario.

\section{La semiosis irónica}

A sabiendas de que en la cadena la forma se proyecta sobre la sustancia, Hjelmslev reduce la función de signo a los niveles formales de ambos planos. Signo es, para él, la forma de significar una sustancia, un paradigma seleccionado del inventario de signos del sistema al que se atribuyen funciones lógico-sintácticas en el proceso. Para los casos en que no hay mutaciones, es decir, ni una alteración significativa del orden sintáctico, ni un "cambio de un miembro de un paradigma por otro miembro perteneciente a un paradigma diverso" (Pascual Buxó: 31), la glosemática emplea el término sustitución (Hjelmslev 1974: 105-08). Así en la denotación, donde las formas expresiva y semántica se seleccionan ambas de inventarios convencionales cuyos elementos equivalentes pueden sustituirse unos por otros sin afectar significativamente a su contraparte (Malmberg: 164). Por su parte, la expresión irónica aparenta ser una cadena cuando en realidad da cuenta de un paradigma. Contiene en sí misma una relación y, oculta, una correlación que vuelca la sustancia hacia adentro mediante la oposición de dos elementos que, en la forma, aparecen unidos por un nexo de semejanza. El contraste interno de la forma conmuta en la oposición sustancial al tiempo que su carácter combinatorio permuta en la semejanza de los elementos contrapuestos; todo ello sin salir del plano cenemático. ${ }^{14}$ En el plano del

14 “Una oposición lingüística — dice Hjelmslev (1972: 114)—, tal como se observa en la sustancia, es pues el reflejo de la correlación entre los miembros de un paradigma. 
contenido, la anomalía se duplica e invierte. La forma léxico-gramatical resultante del contraste de lo semejante se relaciona con la sustancia lógico-semántica de una forma distinta, si bien ésta no se hace presente, sino que sus constituyentes contaminan al exponente dado. En tal caso, el sintagma cumple una doble función paradigmática al oponer una forma semejante y asociar una sustancia distinta, desempeño que, a la permutación de la sustancia en su paso de la expresión al contenido (el contraste de lo semejante), añade una conmutación heredada de la forma (su bivocalidad). Esta interferencia lógica en el nivel morfémico es recíproca, pues la sustancia semántica acaba situándose en un punto medio entre dos exponentes distintos; esto es, en el vacío. ${ }^{15}$

El análisis lingüístico convencional tasa el cambio significativo en el efecto que ocasiona, en los elementos de un plano, la sustitución de unidades en el otro. En el modo irónico, permutación y conmutación se manifiestan ya en el interior del plano cenemático, que a causa de ello se convierte, por derecho propio, en una semiótica según la definición de Hjelmslev (cfr. 1974: 150). La doble operación sustancial de una expresión irónica, contrastada y semejante a la vez, deriva en una función diacrítica mediante la que, como el acento que en el español distingue pronombres y adjetivos, la expresión se vuelve autosuficiente para significar. Siendo, en tanto que figuración, autosignificativa, su caso equivale, diría Hjelmslev, al de una semiótica connotativa. ${ }^{16}$ ¿Cómo se entera el lector? Por la semejanza internamente contrastada

Sólo podemos encontrarla partiendo del hecho mismo del paradigma, es decir de la función de forma, para describir según un procedimiento deductivo cómo ese paradigma se manifiesta a la sustancia".

${ }^{15}$ Lo sabe Linda Hutcheon cuando, situándolo en el entrecruce de lo dicho y lo no dicho, considera necesario no renunciar a la denotación para acceder al significado irónico. El hecho, en primer lugar, de que ninguna ironía cumpla su función mientras no se la decodifique, la dualidad o multiplicidad de su significado, en segundo, y la marca de diferencia o contraste en su interior, en tercero, son los factores que conducen a la canadiense a distinguir tres cualidades fundamentales de la ironía: relacional, inclusiva y diferencial (cfr. 57-66, 176-204).

16 "Para Hjelmslev — dice Pascual Buxó (28 n.) —, las semióticas connotativas contienen derivados de sistemas diferentes de aquel que rige principalmente a un proceso; de ahí que varias partes o partes de partes de un texto puedan componerse en formas estilísticas diferentes, estilos axiológicos diferentes, medios diferentes (habla, escritura, gestos, código de señales, etcétera), tonos diferentes y aun idiomas diferentes". 
de la forma, un indicador que, bajo ciertas condiciones estandarizadas mas no forzosamente convencionales, se desplaza de un nivel al otro; no en balde asegura el danés que "la solidaridad que existe entre ciertas clases de signos y ciertos connotadores es una función de signo, puesto que las clases de signos son expresión de los connotadores como contenido" (1974: 165). ${ }^{17}$

Pero si la expresión irónica es una semiótica, asimismo lo es su contenido, en cuyo plano se da una interferencia de los niveles morfémico y plerémico que también actúa como connotador. Este roce delata la reciprocidad de las dos maniobras que efectúa el contenido irónico: la parodia y la sátira. Sátira y parodia no existen una sin otra, como opina Gerard Genette, ya que todo contenido irónico entraña una imitación estilizada del lenguaje y una crítica velada del mundo. ${ }^{18}$ Más aún, el grado de distorsión de la réplica conduce a una crítica sustancial del lenguaje,

${ }_{17}$ Se trata, así el contraste en el ejemplo expuesto, de prosodemas que actúan como connotadores de la expresión, susceptibles de ser analizados lingüísticamente.

${ }^{18}$ Para Genette (23-44), la distinción entre ambas radica en la clase de relación que guarda el texto imitante con su modelo y, por tanto, en la función discursiva que está llamado a desempeñar. Si un texto desvía el sentido de su fuente o la rebaja, se dice que la transforma, mientras que se habla de imitación si sólo la explota en lo estilístico. Así las cosas, Genette define la parodia como resultado de un mínimo de transformación, y el travestimiento como la transformación que obedece a una función degradante; en contraparte, llama imitación satírica a la emulación con función crítica, y pastiche a la imitación que no cumple tal función. Esto lo conduce a un cuadro estructural en el que las relaciones de transformación, según si cumplen o no una función satírica, dan como resultado el travestimiento y la parodia, mientras que las de imitación, en el mismo orden, derivan en la imitación satírica y el pastiche. Finalmente, sustituye la categoría de función por la de régimen - enumera seis, incluido el irónico- para concluir que lo satírico se opone a lo lúdico, rango, este último, atribuido a la parodia. Convengo, de entrada, en que lo satírico atañe ante todo a lo material y por ello se hace presente en el sintagma, en el proceso de la comunicación, y en que lo paródico tiende a sujetarse al tipo de correlación dada entre los miembros del paradigma. Pero de ahí a que la parodia sea transformadora sin observar una función satírica dista un largo trecho pues, como señala Víctor Bravo, "la parodia es imitación para, en el mismo instante, ser transformación. De allí que sea a la vez homenaje y crítica del objeto parodiado" (117). Tan largo como contemplar la posibilidad de que una imitación satírica no transforme el sentido de su fuente. Una transformación no satírica como la que el francés atribuye a la parodia supone la total autonomía de ésta respecto a su modelo, lo que equivale a decir que el Quijote no es un libro de caballería. Asimismo, la sátira entendida como crítica sin transformación podría conducir al error de no percibir que, en el Coloquio de los perros, el discurso del criado se transforma en el de un elocuente cuadrúpedo. 
tanto del texto como de la lengua, y la crítica del mundo comprende una imitación formal del mismo. ${ }^{19}$ Para burlarse del lenguaje, se lo critica; para criticar al mundo, se hace mofa de él. A ello se refiere Walter Nash cuando asegura que "la parodia se convierte en un arma satírica cuando al parodista le molestan las actitudes, los argumentos o la filosofía de un autor" (85), a lo que cabría añadir que la sátira se convierte en un disfraz paródico ahí donde el satirista se burla de las actitudes, los argumentos y la filosofía del mundo. Parodia y sátira efectúan, cada una, dos operaciones sintagmáticas y dos operaciones paradigmáticas, de modo que la forma del contenido se torna cualitativamente dual y su sustancia resulta dual en un sentido cuantitativo.

Una cadena significante que significa algo distinto de lo que enuncia obtiene un derecho propio. Es a la vez ella y otra. Suena a un tiempo de dos maneras: su forma se desdobla en expresión y contenido. Si, en el otro plano, una cadena de significados expresa algo distinto de lo que contiene, alcanza también su propio estatuto. También es ella y algo más. Contiene dos materiales: su sustancia se desdobla en expresión y contenido, de lo que se sigue que, en la ironía, convergen una semiótica connotativa y una semiótica metalingüística. La inversión controlada de los ejes lingüísticos y de sus funciones autoriza a una semiótica expresiva a emplear otra semiótica como contenido, y a una semiótica semántica a emplear como expresión a aquella (cfr. Hjelmslev 1974: 167-73). La primera pende del coaccionar de un exponente semejante internamente contrastado, de una mención ecoica, y de la consecuente oposición de dos constituyentes semejantes, de una diacrítica, mientras que la segunda habita en la confluencia a la vez dialéctica y dialógica de una parodia y una sátira.

Contemplo aquí uno de aquellos enunciados que Quintiliano denominaba tropos irónicos (ver Institutionis: VIII 6, 54), donde en efecto entra en juego el sentido de las palabras próximas entre sí (ver Beristáin: 277), pero ello no impide que el análisis lo admita cualquiera de las llamadas figuras irónicas. Y es que la ironía no constituye en sí misma

19 El pensar irónico supone, opina Bravo, "no sólo una crítica a lo real sino también una crítica al lenguaje: el cuestionamiento de sus procesos de identificación y el hallazgo, en el lenguaje mismo, de vertientes de diferenciación desde donde es posible nombrar la dualidad y la escisión del ser y del mundo" (1997: 14). 
ni un tropo de dicción ni una figura de pensamiento, sino una función lingüística que puede actuar sobre uno u otro o sobre ambos. De hecho, en el ejemplo de Cortázar, el sentido irónico actúa sobre una comparación figurada que, estructuralmente, poco difiere de un simil como "fiel como un ruiseñor". En este sentido puede decirse que el enunciado es un metasemema, en tanto que la forma mal aliento, comparada con la fidelidad, opera un cambio en el sentido de ésta y al mismo tiempo aparece en sustitución de otra, como una metáfora de algo más. Como la alegoría y la paradoja, la ironía emplea los procedimientos del lenguaje figurado, de modo que, así el de aquellas, su sentido se construye mediante procesos de adjunción y supresión, de semejanza y distinción. Ocurre, no obstante, que en su caso estas maniobras son guiadas por una función lógica de carga negativa que, amén de mostrarse estilísticamente como contraste, ${ }^{20}$ afecta no sólo al sentido sino, paralelamente,

${ }^{20}$ Ballart (324-55) advierte tres posibilidades estilísticas para detectar una ironía, según si el contraste aparece entre elementos del mismo texto, si es reflejo de una discontinuidad entre el texto y su contexto inmediato o bien entre el texto y otro texto. En cuanto a esta última, me parece claro que en toda ironía coactúan, cuando menos, dos textos. Por lo que se refiere al contexto, resulta evidente que cualquier discontinuidad con el texto, para ser significante, ha de reflejarse en una discordancia interna de este último. Una expresión como “¡Buena la has hecho!”, con la que, en El abuelo de Pérez Galdós, Nelly reprende a su hermana por haber lanzado el libro de la lección por los aires, indica una discordancia con la situación en que es enunciada; sin embargo, para ser comprendida como irónica se la ha de contrastar internamente hasta hacerla decir que "buena" no es precisamente como la ha hecho Dolly, contraste en cuya ausencia resulta probable que la expresión pase por un disparate. En cualquier caso, el contexto es suplementario, puede incidir o no, mientras que la oposición interna del texto no lo es, pues de ella depende que su sentido irónico, su función de signo, se ponga en marcha. En adenda, Ballart pone en práctica el modelo de Hjelmslev para distinguir tres clases de desacuerdos del texto consigo mismo: uno que opone la forma de la expresión a la sustancia del contenido, cuyo exponente más vistoso sería la antífrasis, otro cuyo contraste se presenta entre dos elementos de la forma de la expresión, y un tercero, reflejo de la discordancia entre dos elementos de la forma del contenido. Sólo un necio negaría que el ejemplo de Cortázar pertenece al segundo grupo, por cuanto el elemento fiel de la forma expresiva se contrasta con el elemento mal aliento; empleado, no obstante, para designar un constituyente semántico semejante a [pertinaz como el mal aliento], el exponente léxico-gramatical fiel como el mal aliento señala un contraste con otra u otras formas que, aun sin hacerse presentes, alumbran el contorno de un inventario léxicogramatical. Eso, por un lado; por el otro, no se puede negar que la forma de la expresión fiel como el mal aliento marca un contraste con respecto a una sustancia del contenido como [pertinaz como el mal aliento], hacia la que apunta la semiosis irónica. Habida 
al significado, ocasionando un cambio en la lógica del pensamiento que avalaría su inclusión en el catálogo de los metalogismos; sin embargo, el análisis demuestra que también depende de los morfemas para significar, de modo que tampoco cabe en tal categoría.

No cabe porque, como en toda función poética del lenguaje, el contraste de la forma deposita el énfasis en la expresión misma, pero al ser elevada al grado de la mención, la expresión cumple asimismo una función metalingüística en atención al código en que se transmite. La ironía depende, para significar, de la articulación negativa de estas dos funciones, poética y metalingüística, con el agravante de que, como señala Roman Jakobson, "la poesía y el metalenguaje están diametralmente opuestos: en el metalenguaje la secuencia se emplea para construir una ecuación, mientras que en la poesía la ecuación se emplea para construir una secuencia" (361). He ahí la doble operación que pone en marcha la ironía, a un tiempo apropiada e inapropiada, a la vez positiva y negativa, pues si "la función poética proyecta el principio de la equivalencia del eje de selección al eje de combinación" (360), entonces el metalenguaje traslada el principio de contigüidad del eje de combinación al eje de selección. La ironía pertenece, así, al "tipo de semióticas que tienen una semiótica connotativa por expresión y una metasemiótica no científica por contenido" (Pascual Buxó: 74), a lo que se agrega el carácter negativo de su articulación, diacrítico en tanto que ambas semióticas se demarcan mutua y recíprocamente.

cuenta, asimismo, de que no contiene rasgos estilísticos que señalen un conflicto entre elementos de la forma expresiva, una confesión como la del narrador de Los relámpagos de agosto, de Jorge Ibargúengoitia, "mi honradez a toda prueba, que en ocasiones llegó a acarrearme dificultades con la Policía", habría de incluirse en el primer grupo. En el plano de la expresión no parece darse, a primera vista, un choque entre formas estilísticas, estilos axiológicos, medios, tonos o idiomas diferentes, por lo que cabría suponer que el conflicto se refleja directamente sobre el aspecto sustancial del contenido, pero, ojo, si se mira con cuidado salta a la vista que, en la forma expresiva, el elemento honradez es un impostor, lo que se comprende al observar la función que desempeña en el sintagma, en el que se le asocian atributos incompatibles. Ocurre ahí que, como en toda ironía, el plano del contenido actúa como un connotador que afecta a la forma de la expresión y autoriza a percibir un contraste entre sus elementos. Me sorprende que, habiendo comprendido que la instancia rectora del sentido irónico es el contraste, Ballart haya dejado de notar que éste se manifiesta en todos los niveles del signo. 
He escogido, por otra parte, una ironía relativamente estable a sabiendas de que otros ejemplos, no tan precisos, habrían arrojado menos luz al análisis. De cualquier modo, me parece evidente que la sustancia del contenido irónico termina situándose en un punto intermedio entre, al menos, dos formas de contenido, entre las que, según el grado de negatividad de la diacrítica, puede haber poca o mucha distancia. ${ }^{21}$ En el ejemplo citado, el grado de negatividad es mediano. No es en realidad el punto medio entre fiel como el mal aliento y pertinaz como el mal aliento donde se sitúa el significado; lo hace, antes bien, entre aquella y un número probable pero medianamente acotado de formas (es más probable que sea ésta y no otras como devoto como el mal aliento). La estabilidad de la ironía depende de ello: a mayor rango de probabilidad, mayor estabilidad; a menor rango, menos estabilidad. Más que un mero accesorio, el gradiente resulta clave en virtud de las operaciones elementales de la sátira y la parodia, para comprender las cuales cabe echar mano, y no por capricho, de la jerga teatral: ahí donde, puesto que apela a la presencia de la imitación, la parodia se pone en escena, la sátira permanece tras bastidores, cuidando siempre de ocultar la crítica. ${ }^{22}$ Así, pues, cuanto más evidente la imitación, más se restringe la crítica y se gana estabilidad; conforme, a cambio, la crítica se amplía, más se oculta la imitación y más ambigua se torna la ironía. Lejos de significar que la sátira sea oscura y la parodia evidente, lo anterior quiere decir simplemente que conforme mayores son los rasgos paródicos de un mensaje, conforme más se pone éste en escena o, en palabras de Douglas Muecke (cfr. 1969: 119-22), más se identifica a la víctima, con mayor claridad aparece el sentido, que se oscurece en la medida en que aumentan los rasgos satíricos. ${ }^{23}$

21 “Todo acto cultural — señala Mijaíl Bajtín (31) — vive esencialmente sobre fronteras: en esto radica su seriedad y significación. Abstraído de éstas, pierde el terreno, se hace vacío, arrogante, degenera y muere".

22 Esto evidencia, una vez más, la inversión entre lo que se dice y lo que se calla distintiva de la ironía, ya que, con su presencia material, es la cadena la que regularmente cumple una función positiva, opuesta a la ausencia factual del sistema, cuyas operaciones quedan en la sombra.

${ }^{23}$ A propósito, José Ferrater Mora propone distinguir la ironía de acuerdo con su mayor o menor tendencia "hacia la revelación o hacia la deformación, hacía la oblicua descripción o la extrema caricatura" (47). 


\section{La ironía en el marco de la semiolingüística}

Pese a sus ventajas en cuanto a claridad y precisión, lo cierto es que en la vida diaria rara vez empleamos el lenguaje denotado, rara vez, diría Jakobson, la función referencial borra al resto de las funciones. En la vida real cuesta trabajo hallar intercambios de mensajes cuyos planos observen una solidaridad sustitutiva y que, por tanto, efectúen ambos operaciones análogas. Estrictamente hablando no existen las equivalencias absolutas: ni hay tal cosa como la auténtica sinonimia ni una lengua es completamente traducible a las otras (cfr. Hjelmslev 1974: 109-13).

Nietzsche no es el único en advertir esta propiedad del lenguaje, pero sí uno de los más agudos cuando señala que toda palabra es susceptible de convertirse en concepto, pues "no ha de servir para la experiencia singular y completamente individualizada a la que debe su origen $[\ldots]$ sino que debe encajar al mismo tiempo con innumerables experiencias, por así decirlo, más o menos similares, jamás idénticas estrictamente hablando", y remata: "Todo concepto se forma por equiparación de casos no iguales" (1990: 23), donde concepto es sinónimo de símbolo o analogía. ${ }^{24} \mathrm{Ni}$ siquiera un enunciado como "las visitas de Bruno causan aversión" emplea realmente la modalidad mimética del lenguaje (ap. De Man: 246, 250), como sí hace, por ejemplo, "Bruno nos visita", en el que la acción ligada al nombre constituye un valor estable, una constante cuyo rango de variación, como en el lenguaje binario de la informática, sólo admite su contrario ("Bruno se ausenta"), sin medios tonos, y que por ello se equipara al nombre sin sumarle ni restarle un valor agregado. Mientras al nos visita no se le añada un sentido que no sea el suyo propio, Bruno no será más ni menos, mayor ni menor, mejor

${ }^{24}$ Para Nietzsche, la verdad es una "hueste en movimiento de metáforas, metonimias, antropomorfismos, en resumidas cuentas, una suma de relaciones humanas que han sido realzadas, extrapoladas y adornadas poética y retóricamente y que, después de un prolongado uso, un pueblo considera firmes, canónicas y vinculantes" (1990: 25), palabras cuyo eco se escucha, aunque, claro, sin el irónico desdén por lo poético, en estas otras de Octavio Paz: "El mundo no es un conjunto de cosas, sino de signos: lo que llamamos cosas son palabras. Una montaña es una palabra, un río es otra palabra, un paisaje es una frase [...] El texto que es el mundo no es un texto único: cada página es la traducción y la metamorfosis de otra y así sucesivamente. El mundo es la metáfora de una metáfora" (106). 
ni peor, más cálido ni más frío por el hecho de "visitarnos"; mientras ello no ocurra no desaparecerá la interdependencia entre las dos constantes de valor positivo (Bruno = nos visita). A cambio, en "la presencia de Bruno desagrada", el constituyente semántico [desagrada] supone una variable de valor negativo que, al ligarse a él, imprime al nombre un rango de variación análogo. Contaminada por su complemento, la variable nominal disminuye su propio valor hasta estabilizarse en un campo semántico regulado por el referente, toda vez que el rango de variabilidad del complemento es muy amplio: puede uno oler mal, resultar antipático o de plano insoportable. La variabilidad que va de "las visitas diarias de Bruno" a su "fidelidad" es paralela, aunque inversa, en su desplazamiento hacia lo positivo y, en su coaccionar con aque1la, posibilita un enunciado como "Bruno es fiel como el mal aliento", en el que el valor se desplaza a lo positivo, de ahí a lo negativo y, al final, permanece en la negatividad. ${ }^{25}$ Un camino que, desde luego, puede recorrerse a la inversa, como cuando se elogia con un reproche, en "Bruno es obstinado como un ángel guardián", donde, colocado frente a un espejo como el que Nietzsche (1990: 36) atribuye a la ironía, el desplazamiento equivale al del enunciado empleado por Johnny. De lo anterior se deduce que, siempre que en una cadena se halle una correlación oculta entre dos variables, podrá hablarse de ironía, tal como se habla de alegoría cuando, entre las dos constantes de un paradigma, se descubre una relación, de ahí que De Man (250-51) distinga la diacronía narrativa de la segunda del carácter sincrónico de la primera, cuyo sentido derivado se descubre en tiempo real tal como la representación teatral se desarrolla en un presente continuo.

No es, entonces, "pertinaz como el mal aliento" la última reducción a la función referencial que puede hacérsele al comentario de Johnny. Probablemente lo sea una semejante a "las visitas diarias de Bruno desagradan"; más cercana, sin duda, pero difícilmente será la última, a propósito de lo que opina Wayne Booth (296-97) sobre el proceso de interpretación de la ironía. Y es que, al contrario de lo que piensa el de Chicago, toda ironía, por inestable que parezca, tiende a la estabilidad,

${ }^{25}$ Para una definición oportuna de constante y variable, ver Wittgenstein, Tractatus: 3.313-3.317. 
tiende a ser descifrada. Un enunciado puede ser intencionalmente irónico, puede incluso ser irónico per se, pero la naturalización de su significado tocará siempre a quien lo decodifique. El texto extenderá siempre la invitación a realizar nuevas demoliciones y reconstrucciones; es su destinatario quien, consciente o inconscientemente, debe decidir dónde y cuándo detenerse. Cabe, pues, distinguir entre la naturaleza irónica de un mensaje dado, cualidad del todo ligada a las operaciones del lenguaje, y el significado o significados que el receptor selecciona de un catálogo convencional medianamente acotado. Si el lector de Cortázar leyera un enunciado como "Bruno nos visita" difícilmente se toparía con dificultades para atribuirle un contenido acorde con el código más elemental de la lengua, pero tratándose de la expresión empleada por Johnny, antes debe descubrir un segundo código, oculto en el interior de la forma; una plataforma semiótica que surge no ya del contraste de la forma con respecto a otras formas distintas, sino del contraste de la forma consigo misma o, bien, con un doble de sí misma.

Con lo expuesto basta, creo, para comprender que, como todo lenguaje, el sentido figurado está anclado a la asignación de valores y que, siendo así, la ironía constituye la figuración negativa de mayor elevación, de ahí que, cuando la define por oposición a la analogía, Paz resulte impreciso. ${ }^{26}$ Considerando que el uso está reservado para enunciados del tipo de "Bruno nos visita", la figuración se desplazaría en sentido contrario al de la expresión de Johnny con sólo atribuir un valor positivo a las visitas de su amigo. De igual modo que "las visitas de Bruno desagradan" puede transitar de la negación a la ironía pasando por la crítica, un mensaje como "las visitas de Bruno causan alegría" resulta susceptible de estilizarse para hacerlo pasar de la simple afirmación a la analogía y de ahí a la alegoría. Por tal camino se llega fácilmente a "las visitas diarias de Bruno son agradables" y a "la fidelidad de Bruno es agradable", casos típicos del lenguaje analógico, y de ahí a "Bruno es

${ }^{26}$ Opuesta a la analogía se halla, en realidad, la crítica, en la misma medida en que la ironía se opone a la alegoría. Si la analogía "es el reino de la palabra como, ese puente verbal que, sin suprimirlas, reconcilia las diferencias y las oposiciones" (Paz: 100), es decir, el reino de la comparación, entonces su opuesto ha de ser el reino de la distinción, de la separación, de la crisis, donde las semejanzas y equivalencias entran en disputa. 
fiel como un ángel guardián" o "Bruno es fiel como un ruiseñor", resta sólo un paso, el que separa la analogía de la alegoría.

\section{Funciones del signo irónico}

Ahí donde, en el caso de la alegoría, la expresión desempeña una función poética que obliga al contenido a hallar el vínculo mimético entre una forma no expresada y una sustancia derivada, tratándose de la ironía estos dos desplazamientos se efectúan al interior del plano expresivo. Cierto que la mera forma expresiva es ya metalingüística por cuanto tiene de mención, pero también que la referencia al código se resuelve al sopesar la influencia del plano semántico sobre el expresivo. La calidad de mención del mensaje se advierte de inicio, pero la sustancia que predomina es la del eco, la del disfraz, cuya función es propiciar la oposición al interior de la expresión. El segundo código se hace presente únicamente al comprender la naturaleza tópica del contraste, cuando sale a la luz la actitud precisa del eco con respecto a la mención y la metasemiótica comienza a hablar del código poético. Más aún, este peso del plano del contenido sobre el de la expresión hace de la palabra irónica una entidad estética, comprendida ésta como la suma de la imagen poética y su comentario. Toda expresión constituye una imagen de sí misma, una imitación de la lengua, pero la palabra irónica constituye una imagen estética porque, a la crítica de la expresión, a la imitación misma, le agrega la crítica de la imitación, y ello sin salirse de los límites estructurales del plano cenemático. ${ }^{27}$

En contraparte de la función estética de la expresión, la naturaleza metalingüística del contenido cumple una función ética que tiene que ver con la crítica del código y con la crítica del mundo. Puesto que la segunda no tiene estructura, únicamente la primera admite una perspectiva formalista, y aun así, sólo de manera parcial, en la medida en que se critica la forma del código. La crítica de la sustancia, que es, no cabe

27 Comprendo lo estético, grosso modo, tal como lo hace Lev Vigotski (86 ss.), quien lo deriva de una oposición entre la forma y el material que identifica primero en la fábula, luego en otros géneros literarios y, finalmente, en toda obra de arte que se precie de serlo. 
duda, una función lingüística, paradójicamente trasciende el marco de la lengua e incluso del lenguaje; está sujeta a una clase particular de relación entre un mundo y un sujeto, es ya esa relación. Que no posee estructura positiva, se atestigua en el hecho de que su sentido lógico no alcanza a hacerse presente, dejando como hace un vacío sustancial, una negatividad de la sustancia. La forma del contenido irónico se puede abordar, así, desde la estilística, pero su sustancia compete a la filosofía, en particular a la ética. ${ }^{28}$

Con todo, la expresión y el contenido irónicos podrán tener sentido en sí mismos, pero renunciarían a la referencia de no trascender los límites del signo para dirigirse al mundo: "toda conducta verbal — dice Jakobson - se orienta a un fin" (349). Es entonces cuando cobra relevancia el contexto como parámetro para reducir los mensajes a su función referencial, una operación necesaria y constitutiva de la significación. El lenguaje siempre dice algo de algo, por eso asegura Hjelmslev que "totalmente aislado, ningún signo tiene significación; toda significación del signo ocurre en el contexto" (1974: 70). ${ }^{29}$ La ironía no es la excepción a la regla. Se orienta a un fin: la crítica, pero lo hace soterradamente; es, válgase la figura, una central de inteligencia al servicio de la crítica.

He tratado, por último, de ir hilvanando una concepción de la teatralidad al análisis del signo irónico mínimo con el objeto de que se comprenda que en ambos casos se trata de una y la misma cosa. Ello, insisto, siempre y cuando en la ironía verbal se identifique una reducción semiótica de los principios básicos del teatro: escena, drama, comedia y tragedia. Quiero decir que, antes que la teatralidad una consecuencia del lenguaje irónico, es éste un resultado de la práctica de representación que, entre los humanos y, más aún, entre los niños, consiste en poner en

${ }^{28}$ Aquí lo ético posee lo mismo un sentido retórico como el que Dubois y sus colaboradores atribuyen al ethos en tanto que estado afectivo suscitado en el receptor de un mensaje y condicionado valorativamente por una serie de parámetros (Groupe $\mu$ : 147), que uno ligado a lo existencial, así el de Kierkegaard en el Postscriptum (449 ss.), donde figura como una postura radicalmente negativa del sujeto ante el mundo.

29 Esto invalida de tajo la noción de contexto como distintiva de la ironía (v. gr., Brooks: 970, y Culler: 219 ss.) Lo cierto es que, tratándose de un factor común a toda significación, no se puede emplear el contexto para definir unas formas del lenguaje en oposición a otras. 
escena un conflicto dramático, un choque de intereses individuales que, en el seno de lo social, únicamente puede resolverse de manera negativa. De otro modo: la ironía llega al lenguaje, al de los niños, por ejemplo, cuando la palabra ha pasado ya por otras figuraciones de menor complejidad como la analogía, la crítica y la alegoría; es decir, cuando se ha vestido ya de todo su ropaje y de todas sus máscaras y, entonces, se la puede poner en escena para que se desenmascare, desdoblándose en aquella vieja dualidad del alazón y el eirón — del simulador y el disimulador - de que habla Aristóteles en su Ética nicomaquea (II 7, 1108a; IV 7, 1127a-b) y que tan fundamental resulta en la órbita teatral, bien se desplace ésta hacia lo cómico, hacia la crítica formal, social, o bien hacia lo trágico, donde la censura se sustancia y se individualiza.

\section{BIBLIOGRAFÍA}

Alarcos Llorach, Emilio. Gramática estructural. Madrid: Gredos, 1969.

Aristóteles. Ética nicomáquea; Ética eudemia. Madrid: Gredos, 1985.

Bajtín, Misaíl. Problemas literarios y estéticos. La Habana: Arte y Literatura, 1986.

Ballart, Pere. Eironeia. La figuración irónica en el discurso literario moderno. Barcelona: Quaderns Crema, 1994.

Barba, Eugenio, and Nicola Savarese. A Dictionary of Theatre Anthropology. The Secret Art of the Performer. New York: Routledge, 1991.

Barthes, Roland. El sistema de la moda. Barcelona: Gustavo Gili, 1978.

Bergson, Henri. Introducción a la metafísica; La risa. México: Porrúa, 1986. Beristáin, Helena. Diccionario de retórica y poética. México: Porrúa, 1997.

Berrendonner, Alain. Elementos de pragmática lingüistica. Buenos Aires: Gedisa, 1987.

Bоoth, Wayne. Retórica de la ironía. Madrid: Taurus, 1986.

Bravo, Víctor. Figuraciones del poder y la ironía. Caracas: Monte Ávila, 1997.

Brooks, Cleant. "Irony as a Principle of Structure", en Critical Theory since Plato, Hazard Adams (ed.). Fort Worth: Harcourt Brace Jovanovich College, 1992. 968-974.

Bubnova, Tatiana. "Voz, sentido y diálogo en Bajtín", en Acta Poética 27: 1 (2006): 97-114.

Collado, Jesús-Antonio. Fundamentos de lingüistica general. Madrid: Gredos, 1974. 
Coseriu, Eugenio. Teoría del lenguaje y lingüistica general. Madrid: Gredos, 1973.

Culler, Jonathan. La poética estructuralista. El estructuralismo, la lingüistica y el estudio de la literatura. Barcelona: Anagrama, 1978.

De Man, Paul. Visión y ceguera. Ensayos sobre la retórica de la crítica contemporánea. San Juan: Universidad de Puerto Rico, 1991.

De Toro, Fernando. Semiótica del teatro. Del texto a la puesta en escena. Buenos Aires: Galerna, 1978.

DerridA, JACQues. La diseminación. Madrid: Fundamentos, 1975.

Domenella, Ana Rosa. "Entre canibalismos y magnicidios", en De la ironía a lo grotesco. México: Universidad Autónoma Metropolitana, 1992. 85116.

Ducrot, Oswald y Tzvetan Todorov. Diccionario enciclopédico de las ciencias del lenguaje. México: Siglo XXI, 1978.

ECo, Umberto. Tratado de semiótica general. México: Debolsillo, 2005.

Ferrater Mora, José. La ironía, la muerte y la admiración. México: Cruz del Sur, 1946.

Fischer-Lichte, Erika. Semiótica del teatro. Madrid: Arco Libros, 1999.

Frye, Northrop. Anatomy of Criticism. Four Essays. New Jersey: Princeton University Press, 1957.

Genette, Gerard. Palimpsestos. La literatura en segundo grado. Madrid: Taurus, 1989.

Grice, Paul. "Logic and Conversation", en Syntax and Semantics 3. Speech Acts, P. Cole and J. L. Morgan (eds.). New York: Academic Press, 1975. 41-59.

Groupe $\mu$. Rhéthoric générale. Paris: Larousse, 1970.

Hegel, Georg W. F. Poética. Buenos Aires: Espasa-Calpe, 1947.

Huelmslev, Louis. Ensayos lingüisticos, volumen 1. Madrid: Gredos, 1972.

HJelmslev, Louis. Ensayos lingüisticos, volumen 2. Madrid: Gredos, 1987.

Huelmslev, Louss. Prolegómenos a una teoría del lenguaje. Madrid: Gredos, 1974.

Hutcheon, Linda. Irony's Edge: The Theory and Politics of Irony. New York: Routledge, 1994.

Jakobson, Roman. Ensayos de lingüística general. México: Planeta/Artemisa, 1986.

KierkegaArd, Soren. Concluding Unscientific Postscript. Princeton: Princeton University Press, 1941.

Lyons, John. Introducción en la lingüística teórica. Barcelona: Teide, 1981.

Malmberg, Bertil. Los nuevos caminos de la lingüistica. México: Siglo XXI, 1990

Muecke, Douglas. The Compass of Irony. London: Methuen, 1969. 
Muecke, Douglas. "Irony Markers", en Poetics 7: 4 (1978): 363-75.

NASH, Walter. The Language of Humor: Style and Technique in Comic Discourse. London: Longman, 1985.

Nietzsche, Friedrich. El nacimiento de la tragedia. Madrid: Alianza, 2000.

NiETZSCHE, Friedrich. Sobre verdad y mentira en sentido extramoral. Madrid: Tecnos, 1990.

Pascual Buxó, José. Las figuraciones del sentido. Ensayos de poética semiológica. México: Fondo de Cultura Económica, 1984.

Paz, Octavio. Los hijos del limo. Barcelona: Seix Barral, 1974.

Pérez Lasheras, Antonio. Fustigat mores. Hacia el concepto de la sátira en el siglo XVII. Zaragoza: Universidad de Zaragoza, 1994.

Platón. Diálogos, volumen 3. Madrid, Gredos, 1986.

Quintiliano, Marco Fabio. Institutionis oratoriae, volumen 1. Salamanca: Universidad Pontificia de Salamanca, 2000.

Rose, Margaret. Parody: Ancient, Modern, and Post-Modern. Cambridge: Cambridge University Press, 1993.

Saussure, Ferdinand de. Curso de lingüistica general. Buenos Aires: Losada, 1967.

Sperber, Dan y Deirdre Wilson. "Les ironies comme mentions", en Poétique 36 (1978): 399-412.

Sperber, Dan y Deirdre Wilson. "Irony and the Use-Mention Distinction", en Radical Pragmatics, P. Cole (ed.). New York: Academic Press, 1981. 295-317.

Staiger, Emil. Conceptos fundamentales de poética. Madrid: Rialp, 1966.

Tinianov, Yuri. "Sobre la evolución literaria", en Teoría de la literatura de los formalistas rusos, Tzvetan Todorov (ed.). México: Siglo XXI, 2007. 89-101.

Vigotski, Lev. Psicología del arte. Barcelona: Paidós, 2006.

Wittgenstein, Ludwig. Tractatus logico-philosophicus. Madrid: Alianza, 2003.

Wolf, Maryanne. Cómo aprendemos a leer. Barcelona: Ediciones B, 2008.

Worcester, DAvid. The Art of Satire. New York: Russell \& Russell, 1960. 
- JuAN CAMPESINO

Licenciado en Literatura y ciencias del lenguaje por la Universidad del Claustro de Sor Juana, maestro en Letras latinoamericanas y doctor en Letras por la Universidad Nacional Autónoma de México. Ha sido becario de la Fundación Telmex, del Centro Mexicano de Escritores, en dos ocasiones, y del CONACYT. Es profesor del Centro de Enseñanza de Lenguas Extranjeras (CELE, UNAM) e investigador del Centro Nacional de Investigación, Información y Documentación Teatral Rodolfo Usigli (CITRU) del INBAL. 